\title{
Emotional maturity, daily hassles stress and economic status among college students
}

\author{
Bhise Sudam Arjun \\ Assistant Professor, K.M.C. College, Khopoli, Taluka Khalapur, District Raigad. \\ Corresponding author: Mr. Bhise Sudam Arjun \\ Email - sudam_bhise@yahoo.co.in
}

\begin{abstract}
Background: The present study compared emotional maturity and daily hassles stress of male and female students coming from different economic status.

Methods: The sample consisted of 200 graduate students from Ahmednagar city from Maharashtra. The age range of the sample was 18-22 years. One hundred of these were from low economic status and remaining hundred were from high economic status. In each group- 50 boys and 50 girls were included. The two tests used for this study were namely, Emotional maturity scale (Taneja, P.2004) and Daily Hassles Scale (Lazarus \& Folkman1989). A 2x2 ANOVA showed significant main effects as well as interaction effect of gender and economic status on emotional maturity and daily hassles stress.

Results: The results showed that economic status was a significant variable, which has proved its significance in the entire study. The mean differences are not significant. Students from low economic status were significantly higher on daily hassles stress than the students from high economic status (F (1, 196) $=10.11, \mathrm{p}<.001)$.

Conclusion:Girls and boys did not differ in daily hassles stress. Student from high economic students were significantly higher on emotional maturity than low economic status students. Girls were not significantly different on emotional maturity than boys.
\end{abstract}

Keywords: Emotional maturity, Daily Hassles Stress, Gender and Economic Status among College Students.

(Paper received $-3^{\text {rd }}$ January 2018, Peer review completed $-7^{\text {th }}$ January 2018)

(Accepted $-10^{\text {th }}$ January 2018)

\section{INTRODUCTION}

Today's rapid urbanization, industrialization, unemployment, and withering social values brought modern man under stress. Stress not only affects his or herhealth but also attitudes, overall conduct and behaviour. According to Colman, "The seventeenth century has been called the Age of Enlightenment, the eighteenth, the Age of Reason, the nineteenth, the Age of progress, and the twentieth, the Age of anxiety, stress, worries, doubts, strain and conflicts" [1].

Much of the stress in our lives results from the way we deal with daily hassles pertaining to our jobs, personal relationship, and everyday living circumstances. Many people experience the same hassles every day for example, noisy neighbourhood, commuting toward workplace in heavy traffic, disliking one's fellow workers, worrying about money, waiting in a long line, and misplacing or losing things. When taken individually these hassles may feel like only minor irritants, but cumulatively, over a period, they can cause significant stress [2].

Palsane and Evans noted that in case of low SES urban individuals, chronic strain was associated with greater level of psychosomatic symptomatology and lower perceived social support [3]. Dubow and Tisel 
(1989) report that exposure to major life events are likely to be associated with emotional difficulties and behavioural maladjustment in children and adolescents.

As reported by Cox, the experience of stress is not usually or simply reported in terms of being stressed, but is more often described in ways associated with emotions, such as anger, anxiety, depression, fear, grief, guilt, jealousy and shame [4]. Impulses and feelings are not wrong of and by themselves, emotions can be either right or wrong, this depends strictly on when and how they are used. Marsella (1994) suggests that stress involves an emotional reaction, especially a reaction involving the negative emotional states [5].

The negative events are likely to be more stressful than positive ones because negative events are unpleasant. People cannot easily overcome these negative events as they are not ready for it. It has been found that exposure to major life events are likely to be associated with emotional difficulties and behavioural maladjustment in children and adolescents.

So, the present study is planned to gain some insight into the differences in emotional maturity and daily hassles stress in relation to economic status and gender of the participants.

The main objectives of the study were as follows -

1) To study the gender differences in emotional maturity and daily hassles stress.

2) To compare the students with low economic status and high economic status on emotional maturity and daily hassles stress.

Based on the earlier researches the following hypotheses were proposed.

\section{Hypotheses}

1) Girls have more emotional maturity than boys.

2) Girls have less daily hassles stress than boys.

3) Emotional maturity is higher among the students of high economic status than the students of low economic status.

4) Daily hassles stress is higher among the students of low economic status than the students of high economic status.

\section{METHODOLOGY}

\section{Participants}

There were 200 graduate students from Ahmednagar city of Maharashtra who participated in the study. The age range of the participants was 18-22 years. One hundred of these were from low economic status and remaining hundred were from high economic status. In each group 50 were boys and 50 were girls.

Based on this low and high economic status is decided by the state government and accordingly family is given either a yellow or white ration card. These cards are given on the basis of annual income of the family.

\section{Tools}

\section{Emotional Maturity Scale}

There are very few scales available on emotional maturity, one of which was developed by Singh and Bhargava which contains five factors namely: emotional instability, emotional regression, social maladjustment, personality disintegration and lack of independence.

Unavailability of an adequate scale for measuring emotional maturity prompted the development of a new tool. This scale is developed by Taneja (2004) based on Singh and Bhargava's Emotional Maturity Scale, which was standardized on 473 female students of Nagpur city. There are 53 items in EMS scale; the scale is to be responded to a 5-point scale ranging from 'almost [6].

\section{Daily Hassles Scale}

Daily Hassles Scale is developed by Lazarus and Folkman [2]. The test consists of 117 items used to measure the frequency of severity of person's transactions with the environment that are considered by the person to be stressful event. This is a four-point rating scale ranging from none or did not occur, somewhat 
severe, moderately severe to extremely severe. The respondent has to indicate whether each item was a hassle or not. If so he/she has to respond in terms of severity on four-point scale.

The test has an evidence of the construct validity where the scale is able to explain or predict psychological symptoms and symptoms of somatic illness and emotional distress. Kanner showed that hassles scores were strongly related to both affective distress and psychological symptoms [7]. The internal consistency reliability obtained was $\mathrm{r}=.96$ and item total correlation values ranged from $\mathrm{r}=0.27$ to 0.63 .

\section{Procedure}

First of all, the permission for data collection was taken from the concerned authorities of the college. Then actual data were collected from the college students of low and high economic status after identifying them with a yellow ration card or white ration card. Emotional maturity scale and Daily Hassles Scale were administered to all students. Personal data sheet, separate answer sheet and tests were given to the students in groups of 20-25 students. The students were informed that they must mention their economic level on the answer sheet. This was verified from the ration card. All instructions were given to students before the testing. After data collection the scoring was done according to the fixed procedures given in the manual of the test.

In the present study along with descriptive statistics like Mean and SD, two-way ANOVA was used to study the gender differences and differences in economic status on emotional maturity and daily hassles stress. Prior to this analysis, normality of the scores distribution was verified.

\section{RESULTS}

Table 1 - Gender differences on the emotional maturity

\begin{tabular}{|c|c|c|c|c|}
\hline Gender & Mean & SD & F & Sig. \\
\hline Boys $(\mathrm{N}=100)$ & 120.10 & 15.33 & 0.364 & $\mathrm{p}>0.547$ \\
\cline { 1 - 2 } Girls $(\mathrm{N}=100)$ & 121.43 & 16.59 & & \\
\hline
\end{tabular}

Mean, SD and $\mathrm{F}$ value for boys and girls on emotional maturity were calculated and presented in Table 1. $\mathrm{SD}$ is so high because of $2 \mathrm{X} 2$ research design which include two hundred students, out of this one hundred were from low economic status and remaining were from high economic status and in each group 50 were boys and 50 were girls. The mean differences are not significant. Therefore, the hypothesis that girls have more emotional maturity than that of boys cannot be accepted.

Table 2 - Gender differences on the Daily hassles stress

\begin{tabular}{|c|c|c|c|c|}
\hline Gender & Mean & SD & F & Sig. \\
\hline Boys $(\mathrm{N}=100)$ & 145.58 & 42076 & 0.566 & 0.453 \\
\hline Girls(N=100) & 150.49 & 52.30 & & \\
\hline
\end{tabular}

To test the hypothesis that "Girls have less daily hassles stress than boys" the 'F' test was calculated and the obtained results are shown in Table 2. It shows that girls have more daily hassles stress than boys. However, the F shows that the difference in Means is not significant. Therefore, this hypothesis that girls have less daily hassles stress than that of boys was rejected. 
Table 3 - Differences in economic status

\begin{tabular}{|c|c|c|c|c|}
\hline Economic status & Mean & SD & F & Sig. \\
\hline High $(\mathrm{N}=100)$ & 124.51 & 15.82 & \multirow{2}{*}{11.54} & $\mathrm{P}<0.001$ \\
\hline Low $(\mathrm{N}=100)$ & 117.2 & 15.26 & & \\
\hline
\end{tabular}

To test the hypothesis that emotional maturity is higher among high economic status students than low economic status students. The ' $\mathrm{F}$ ' was calculated and the results are shown in table no.3.It shows that high economic students are significantly higher on emotional maturity than low economic students. The hypothesis third was accepted.

Table 4 - Differences between low and high economic students on the Daily hassles stress

\begin{tabular}{|c|c|c|c|c|}
\hline Economic status & Mean & SD & F & Sig. \\
\hline High $(\mathrm{N}=100)$ & 137.66 & 40.92 & 10.107 & $\mathrm{p}<0.005$ \\
\cline { 1 - 3 } Low $(\mathrm{N}=100)$ & 158.41 & 51.81 & & \\
\hline
\end{tabular}

To test the differences in the students of low and high economic status on amount of daily hassles stress, the following hypothesis was subjected to the analysis. SD is so high because of $2 \mathrm{X} 2$ research design which include two hundred students, out of this, one hundred were from low economic status and remaining were from high economic status and in each group 50 were boys and 50 were girls. Daily hassles stress is higher among the students of low economic status than the students of high economic status. Table 4 shows that students from low economic status are significantly higher on daily hassles stress than students from high economic status. The hypothesis was accepted.

\section{DISCUSSION}

\section{Gender Differences}

The first hypothesis was that the girls have more emotional maturity than boys. The results showed that the girl's Mean was greater than that of boy's. But it was not statistically significant. Thus, the hypothesis was not verified.

Devi and Venkatramaiah studied male and female students, it showed that females are unstable than male students. The presents findings failed to support this observation [8]. Gender-role socialization may explain sex related differences in emotion. Gender roles are associated with the expression of different emotions [9]. Women's concern with relationship may lead them to express emotions that strengthen relationships and inhibit emotions that could harm relationship [10]. The idea that women express emotions outwardly and men express emotions inwardly suggests the basis of emotional differences for men and women [11]. This could be the reason behind the girls having more emotional maturity than boys.

The second hypothesis was that the girls have less daily hassles stress than boys. The results showed that the girls mean on daily hassles stress was greater than that of boys. But the $\mathrm{F}$ test showed that this difference was not significant. Therefore, this hypothesis that girls have less daily hassles stress was rejected. Although the literature examining the relation between gender and stress reveals several conflicting outcomes, numerous authors have determined that women find themselves in stressful circumstances more often than men [9]. But, Thergaonkar found that boys reported more daily hassles in terms of frequency as well as intensity as compared to girls [11-12].

As far as gender is concerned there are two styles of coping. Men are more likely to tackle stressors and problems by using problem-focused strategies, whereas women are more likely to use emotion focused strategies. This may lead to more emotional distress or daily hassles stress within women. But the findings of this study are not conclusive at this stage. 


\section{Economic Status Differences}

Result shows that economic status is significant variable, which has proved its significance in the entire study. The main objective of the study was to find out the role of economic status and gender in emotional maturity and daily hassles stress among college going students.

The third hypothesis was emotional maturity is higher among the students of high economic status than the students of low economic status. The obtained results showed that high economic status students have greater degree of emotional maturity as compared to low economic status students. The reason behind this finding may be that high SES students get greater opportunities to take new experience from environment. Their parents are also very careful about their children's habits and emotional development. Thus, they get more exposure for developing emotional maturity. These findings show similar results to that of Taneja and other studies [6, 13-14].

Taneja found that emotional maturity was significantly higher among slum dwellers than flat dwellers. So, it can be rationalized that economic status has vital role in exposing individual to environment, with greater openness thus enabling students to strengthen their emotional resources.

The fourth hypothesis related to daily hassles stress was that the daily hassles stress is higher among the students of low economic status than the students of high economic status. This hypothesis is verified. The obtained findings are similar to Evans and English study where they found significant greater financial pressure among low-income group children than their counterparts from the middle-income group [15]. Income has been found to be an important variable for explaining class differences in psychological distress among men, whereas differences in education were more important for women [9]. Students of low economic status are likely to experience greater economic deprivation which is associated with high levels of psychological distress [7]. The economic factor produces varying degree of stress depending upon the nature and type of economic problem imposed upon individuals [14]. So, having inadequate financial resources (low economic status) triggers problems of adjustment, survival and it leads to hassles. The present findings support the earlier researches in this area.

\section{REFERENCES}

1. Coleman JC. Abnormal psychology and modern life. Pearson; 1984.

2. Lazarus RS, Folkman S. Manual Hassles and Uplifts Scales: Sampler Set: Manual and Test Booklet. Mind Garden; 1989.

3. Palsane, MN., \& Evans, GW. Studies in stress and its management. New Delhi: Oxford and IBH; 1991.

4. Cox T, Griffiths A, Rial-González E. Research on work-related stress. European Communities; 2000.

5. Marsella AJ. The measurement of emotional reactions to work: Conceptual, methodological and research issues. Work Stress 1994;8(2):153-76.

6. Taneja. Emotional maturity, personality type (sattva, Rajas and Tamas) and social class as variables in stress wellbeing relationship. 2002. [Unpublished Ph.D. Thesis, University of Pune].

7. Horwitz AV, White HR, Howell-White S. The use of multiple outcomes in stress research: A case study of gender differences in responses to marital dissolution. J Health Soc Behav 1996;9:278-91.

8. Devi UL, Venkatramaiah, P. Emotional maturity level of rural high school children. Relationship with selected with personal social variables. Indian Psychol Rev 1997;48(4):197-201.

9. Matud MP. Gender differences in stress and coping styles. Personal Individ Diff 2004;37(7):1401-15.

10. Timmers M, Fischer AH, Manstead AS. Gender differences in motives for regulating emotions. Personal Soc Psychol Bull 1998;24(9):974-85.

11. Plutchik R. A general psycho-evolutionary theory of emotion. Theories of emotion. 1980.

12. Thenmozhi S. Behaviour Problems and Adjustment Problems of Stepfamily Adolescents in Comparison With Intact Family Adolescents. Indian J Appl Psychol 2001;38:1-6.

13. Narayanan A. Predictors of resilience among adolescents of low socio-economic status in India. Int Rev Psychiatry 2015;27(3):204-17.

14. Agrawal, S. Social Stress and Thyrotoxicosis. Vishwavidyalaya Prakashan, Varansi. 1983.

15. Richardson M, Abraham C, Bond R. Psychological correlates of university students' academic performance: a systematic review and meta-analysis. Psychol Bull 2012;138(2):353-8.

$* * * * * * * * * * * * * * * * * * * * * *$

Acknowledgements - Nil; Conflict of Interest - Nil ; Funding - Nil 